
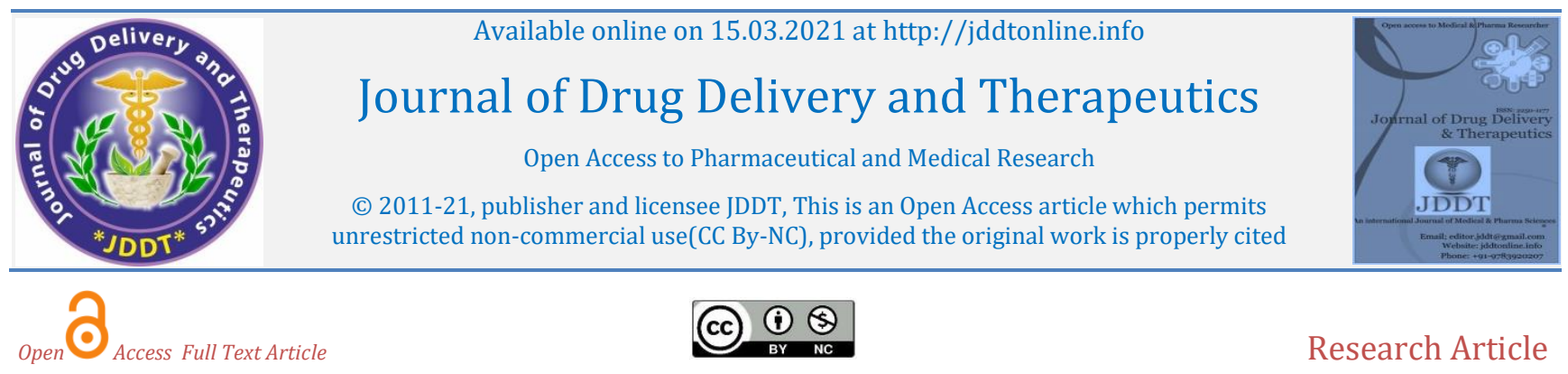

Research Article

\title{
Formulation Development and Evaluation of Liposphere of Poor Water Soluble Drug for Hyperlipidemia
}

\author{
Anil Kumar*, Umesh K. Jain, Ajay Patel \\ Bhopal Institute of Technology and Science, Pharmacy, Bhopal MP India
}

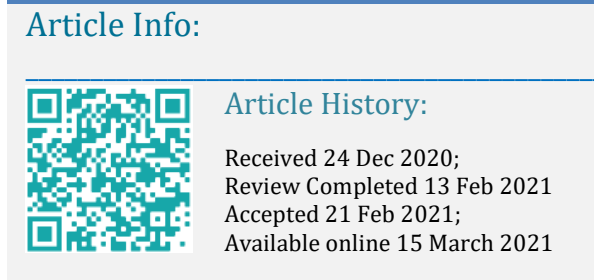

Cite this article as:

Kumar A, Jain UK, Patel A, Formulation Development and Evaluation of Liposphere of Poor Water Soluble

Drug for Hyperlipidemia, Journal of Drug Delivery and Therapeutics. 2021; 11(2):23-30

DOI: http://dx.doi.org/10.22270/jddt.v11i2.4578

\section{*Address for Correspondence:}

Anil Kumar, Bhopal Institute of Technology and Science, Pharmacy, Bhopal MP India

\section{Abstract}

Lipospheres offer a new approach to improve an aqueous solubility of BCS class-II drugs. Simvastatin is a third generation fibric acid derivative belonging to this class, employed clinically as a hypolipidemic agent to lessen the risk caused by atherosclerosis. An attempt was made to improve aqueous solubility of Simvastatin by aid of stearic acid and Paraffin oil. The factorial batches of the Simvastatin lipospheres were formulated by melt dispersion technique using 32 factorial design with variables X1- concentration of stearic acid and X2- concentration of paraffin oil and responses Y1 - \% Drug Entrapment (\% DE) and Y2 - \% Drug Release (\% DR). From the surface response graphs the optimized batch was formulated and evaluated for saturation solubility, in-vitro drug release studies. Significant improvement in the aqueous solubility of the drug in the Simvastatin lipospheres supports the applicability of lipospheres as a tool for improving aqueous solubility of the BCS class-II drugs.

Keywords: Linospheres; Simvastatin; Drug release; Hyperlipidemic; Drug entrapment.

\section{INTRODUCTION}

Hyperlipidemia is a condition excess of fatty substances called lipids, largely cholesterol and triglycerides, in the blood. It is also called hyperlipoproteinemia because these fatty substances travel in the blood attached to proteins. This is the only way that these fatty substances can remain dissolved while in circulation. The most recent cholesterol management guidelines (the third report of the adult treatment panel ATP III), which are issued by the national cholesterol education program (NCEP) in May 2001, redefine the levels at which blood cholesterol should be treated ${ }^{1}$. These new evidence- based recommendations are departure from the NCEP's previous guidelines (ATP II) in several ways. American heart association defined hyperlipidemia is a high level of fats in the blood. These fats, called lipids include cholesterol and triglycerides. There are different types of hyperlipidemia depending on which lipid levels are high in the blood 2-3.

\section{Hyperlipidemia in general can be divided into two subcategories}

Hypercholesterolemia, in which there is a high level of cholesterol and hypertriglyceridemia, in which there is a high level of triglycerides, the most common form of fat.

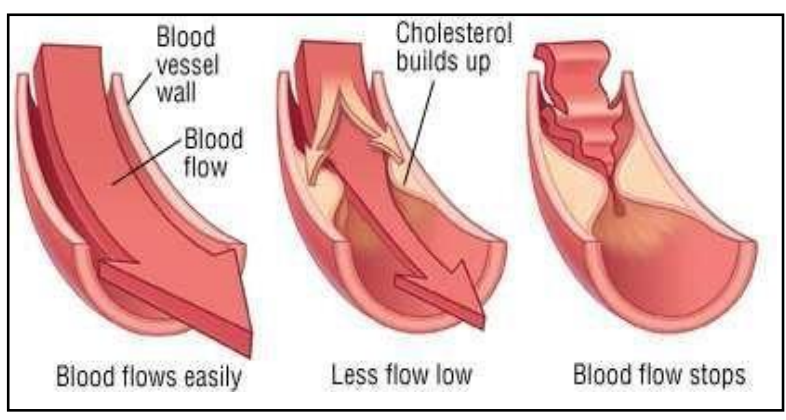

Figure 1: Hypercholesterolemia

The fat-protein complexes in the blood are called lipoproteins. The best- known lipoproteins are LDL (lowdensity lipoprotein) and HDL (high-density lipoprotein). Excess LDL cholesterol contributes to the blockage of arteries, which eventually leads to heart attack. Population studies have clearly shown that the higher the level of LDL cholesterol, the greater the risk of heart disease $4-5$. This is true in men and women, in different racial and ethnic groups, and in all adult age groups. Hence, LDL cholesterol has been labeled the bad cholesterol. In contrast the lower the level of HDL cholesterol, the greater the risk of coronary heart disease. As a result, HDL cholesterol is commonly referred to as the good cholesterol. Low HDL cholesterol levels are typically accompanied by an increase 
in blood triglyceride levels. Studies have shown that high triglyceride levels are associated with an increased risk of coronary heart disease. Although hyperlipidemia does not cause to feel bad, it can significantly increase the risk of developing coronary heart disease, also called coronary artery disease or coronary disease. People with coronary disease develop thickened or hardened arteries in the heart muscle ${ }^{6}$. This can cause chest pain, a heart attack, or both. Because of these risks, treatment is often recommended for people with hyperlipidemia. High lipid levels can speed up a process called atherosclerosis, or hardening of the arteries. Arteries are normally smooth and unobstructed on the inside, but as age goes, a sticky substance called plaque forms in the walls of your arteries. Plaque is made of lipids and other materials circulating in your blood. As more plaque builds up, your arteries can narrow and stiffen. Eventually, enough plaque may build up to reduce blood flow through your arteries 7-8. Hyperlipidemia has been implicated in atherosclerosis, which is the primary cause of heart disease and stroke. Atherosclerosis increases your risk of heart disease, stroke, and other vascular diseases. Fortunately, may be able to reduce high lipid levels and therefore prevent or slow the progression of atherosclerosis. Lifestyle changes like exercising and eating a healthy diet can also lower your lipid levels and are often the first step in treatment ${ }^{9-11}$.

\section{MATERIALS AND METHODS}

\section{Preformulation study}

Preformulation study is the first step in the rational development of dosage form of a drug substance. It can be defined as an investigation of physical and chemical properties a drug substance alone and when combined with excipients. The overall objective of preformulation testing is to generate information useful to the formulator in developing stable \& bioavailable dosage forms which can be mass produced. Obviously, the type of information needed depend on the dosage form to be developed. Preformulation studies include studies of

\section{Characterization of drug}

\section{Physiochemical Properties of Simvastatin}

It refers to the evaluation by sensory characters-taste, appearance, odor, feel of the drug, etc.

Table 1: List of Sensory characters

\begin{tabular}{|l|l|l|}
\hline S. No. & Sensory characters & Result \\
\hline 1. & Colour & White to off-white powder \\
\hline 2. & Odor & Odorless \\
\hline 3. & Taste & Tasteless \\
\hline
\end{tabular}

\section{Solubility}

Solubility of the drug was determined by taking some quantity of drug (about 1-2 mg) in the test tube separately and added the $5 \mathrm{ml}$ of the solvent (water, ethanol, methanol, 0.1N HCL, 0.1N NaOH, Chloroform and $6.8 \mathrm{pH}$ phosphate buffer) Shake vigorously and kept for some time. Note the solubility of the drug in various solvents (at room temperature).
Table 2: Solubility of Simvastatin

\begin{tabular}{|l|l|}
\hline Solvent used & Simvastatin \\
\hline Distilled Water & Sparingly Soluble \\
\hline $0.1 \mathrm{~N}$ Hydrochloric acid & Slightly soluble \\
\hline Ethanol & Freely Soluble \\
\hline Methanol & Freely soluble \\
\hline Chloroform & Soluble \\
\hline $0.1 \mathrm{~N} \mathrm{NaOH}$ & Sparingly Soluble \\
\hline $6.8 \mathrm{pH}$ phosphate buffer & Soluble \\
\hline
\end{tabular}

\section{Melting point}

It is one of the parameters to judge the purity of drugs. In case of pure chemicals, melting points are very sharp and constant. Since the drugs contain the mixed chemicals, they are described with certain range of melting point.

\section{Procedure for determine melting point}

A small quantity of powder was placed into a fusion tube. That tube was placed in the melting point determining apparatus (Chemline) containing castor oil. The temperature of the castor oil was gradual increased automatically and read the temperature at which powder started to melt and the temperature when all the powder gets melted.

Table 3: Melting point of Simvastatin

\begin{tabular}{|c|c|c|}
\hline S. No. & $\begin{array}{c}\text { Melting Point of } \\
\text { Simvastatin }\end{array}$ & $\begin{array}{c}\text { Average M. P. of } \\
\text { Simvastatin }\end{array}$ \\
\hline 1 & $136-138^{\circ} \mathrm{C}$ & \multirow{2}{*}{$136-138^{\circ} \mathrm{C}$} \\
\hline 2 & $137-138^{\circ} \mathrm{C}$ & \\
\hline 3 & $136-138^{\circ} \mathrm{C}$ & \\
\hline
\end{tabular}

\section{Determination of $\mathrm{pH}$ (1 $\mathrm{w} / \mathrm{v}$ solution in water)}

About $100 \mathrm{mg}$ of the Powder was taken and dissolved in $10 \mathrm{ml}$ of distilled water with sonication and filtered. The $\mathrm{pH}$ of the filtrate was checked with standard glass electrode.

Table 4: pH of the Simvastatin

\begin{tabular}{|c|c|c|}
\hline S. No. & pH of the solution & $\begin{array}{c}\text { Average pH of the } \\
\text { solution }\end{array}$ \\
\hline 1 & 7.61 & 7.61 \\
\hline 2 & 7.61 & \\
\hline 3 & 7.5 & \\
\hline
\end{tabular}

\section{FTIR Spectroscopy}

\section{Sample of pure Simvastatin}

The IR spectrum of sample drug shows the peak values which are characteristics of the drug and the graph were shown in figure 1. 


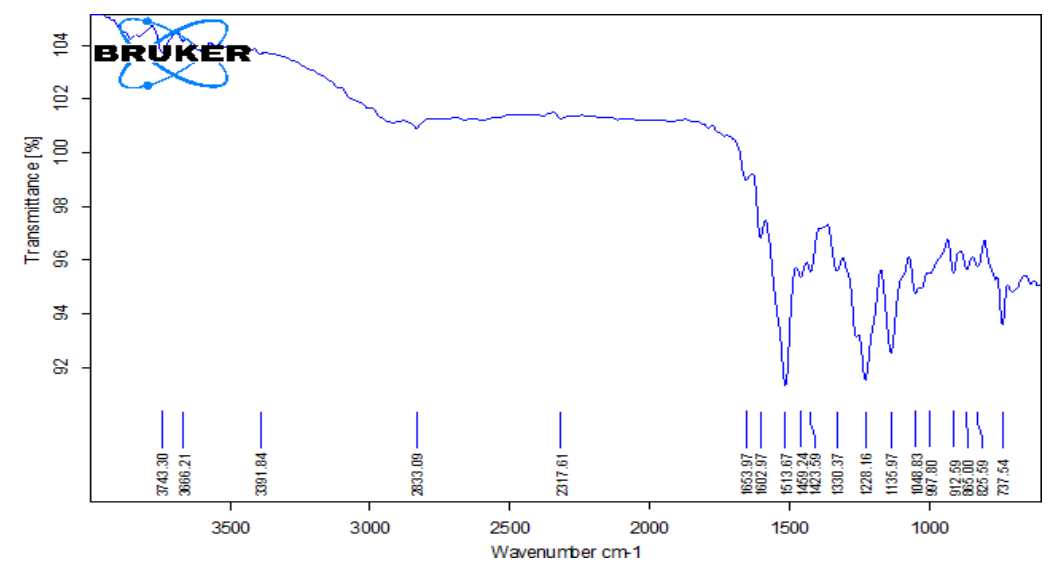

Figure 1: FT-IR Spectrum of Pure Drug (Simvastatin)

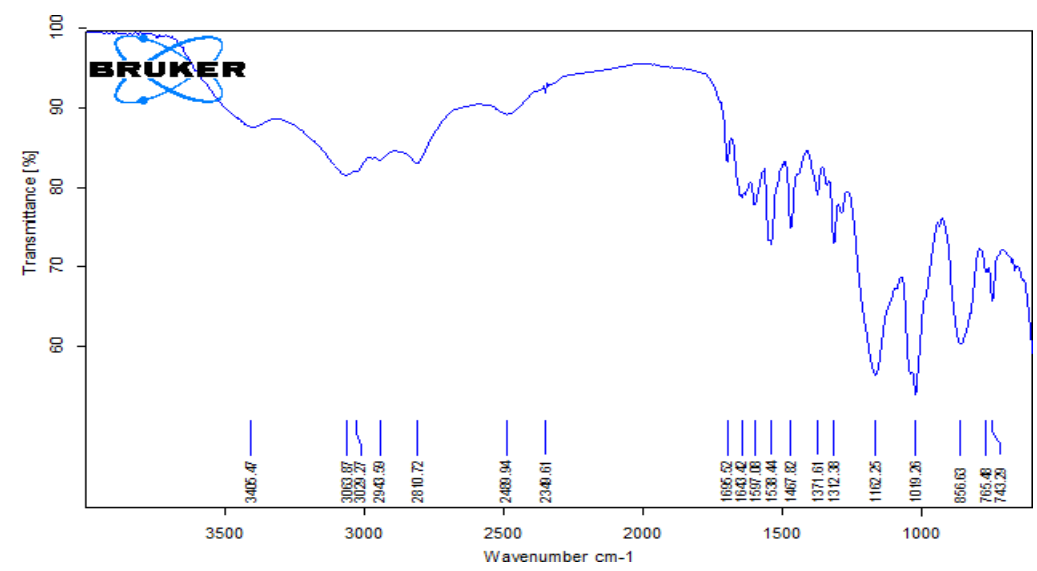

Figure 2: FT-IR Spectrum of Drug and excipients

Loss on drying: The moisture in a solid can be expressed on a wet weight or dry weight basis. On a wet weight basis, the water content of a material is calculated as a percentage of the weight of the wet solid. The term loss on drying is an expression of moisture content on a wet weightbasis.

Bulk properties
Accurately weighed $1 \mathrm{gm}$ of powder was poured into the measuring cylinder carefully level the powder without compacting, if necessary and read the unsettled apparent volume, Vo, to the nearest graduated unit. Calculate the bulk density in gm per $\mathrm{ml}$, gm/cc by the formula

Bulk density = Bulk Mass/ Bulk Volume

Table 5: Bulk density of Simvastatin

\begin{tabular}{|c|c|c|c|c|}
\hline S. No. & Bulk mass & Bulk volume & Bulk density & Avg. bulk density \\
\hline 1. & $1 \mathrm{gm}$ & $3 \mathrm{ml}$ & $0.333 \mathrm{~g} / \mathrm{cm}^{3}$ & \multirow{2}{*}{$0.333 \mathrm{~g} / \mathrm{cm}^{3}$} \\
\cline { 1 - 4 } 2. & $1 \mathrm{gm}$ & $3 \mathrm{ml}$ & $0.333 \mathrm{~g} / \mathrm{cm}^{3}$ & \multirow{2}{*}{$0.322 \mathrm{~g} / \mathrm{cm}^{3}$} \\
\cline { 1 - 3 }. & $1 \mathrm{gm}$ & $3 \mathrm{ml}$ & \\
\hline
\end{tabular}

\section{Tapped density}

Accurately weighed $10 \mathrm{gm}$ of powder was poured into the measuring cylinder carefully level the powder and read the tapped volume (after 50-60 times tapping),
$V_{t}$ to the nearest graduated unit. Calculate the tapped density in gm per $\mathrm{ml}, \mathrm{gm} / \mathrm{cm}^{3}$ by the formula

Tapped density = Bulk Mass $/$ Tapped Volume

Table 6: Tapped density of Simvastatin

\begin{tabular}{|l|l|l|l|l|}
\hline S. No. & Bulk mass & Tapped volume & Tapped density & s. tapped density \\
\hline 1. & $1 \mathrm{gm}$ & $2.8 \mathrm{ml}$ & $0.357 \mathrm{~g} / \mathrm{cm}^{3}$ & $0.357 \mathrm{~g} / \mathrm{cm}^{3}$ \\
\cline { 1 - 4 }. & $1 \mathrm{gm}$ & $2.8 \mathrm{ml}$ & $0.357 \mathrm{~g} / \mathrm{cm}^{3}$ & \\
\cline { 1 - 3 } & $1 \mathrm{gm}$ & $2.7 \mathrm{ml}$ & $0.370 \mathrm{~g} / \mathrm{cm}^{3}$ & \\
\hline
\end{tabular}




\section{Compressibility index (Carr's index)}

Compressibility index (C.I.) is an important measure that can be obtained from the bulk and tapped densities. Carr's index a material having values of less than $20 \%$ to $30 \%$ is defined as the free flowing material.

Table 7: C. I. of Simvastatin

\begin{tabular}{|c|c|c|c|}
\hline S. No. & Bulk density & Tapped density & C.I. \\
\hline 1 & $0.333 \mathrm{~g} / \mathrm{cm}^{3}$ & $0.357 \mathrm{~g} / \mathrm{cm}^{3}$ & 6.722 \\
\hline
\end{tabular}

\section{Hausner's ratio}

It indicates the flow properties of the powder and is measured by the ratio of tapped density to bulk density.

Hausner ratio $=$ Tapped density $/$ Bulk Density

Table 8: Hausner's of Simvastatin

\begin{tabular}{|l|l|l|l|}
\hline S. No. & Bulk density & Tapped density & Hausner ratio \\
\hline $\mathbf{1 .}$ & $0.333 \mathrm{~g} / \mathrm{cm}^{3}$ & $0.357 \mathrm{~g} / \mathrm{cm}^{3}$ & 1.072 \\
\hline
\end{tabular}

\section{Determination of $\lambda_{\max }$ of Simvastatin}

Accurately weighed $10 \mathrm{mg}$ of drug was dissolved in $10 \mathrm{ml}$ of $0.1 \mathrm{~N} \mathrm{HCl}$ solutions in $10 \mathrm{ml}$ of volumetric flask. The resulted solution $1000 \mu \mathrm{g} / \mathrm{ml}$ and dilution to make it to a concentration range of $10-50 \mu \mathrm{g} / \mathrm{ml}$. The spectrum of this solution was run in $200-400 \mathrm{~nm}$ range in U.V. spectrophotometer (Labindia-3000+).

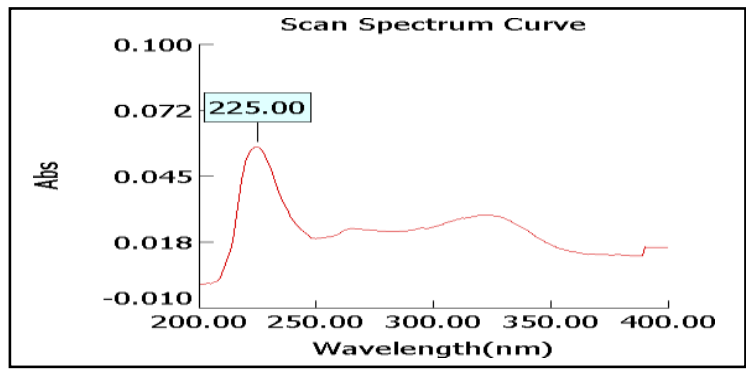

Figure 3: Wavelength maxima of Simvastatin at $225 \mathrm{~nm}$

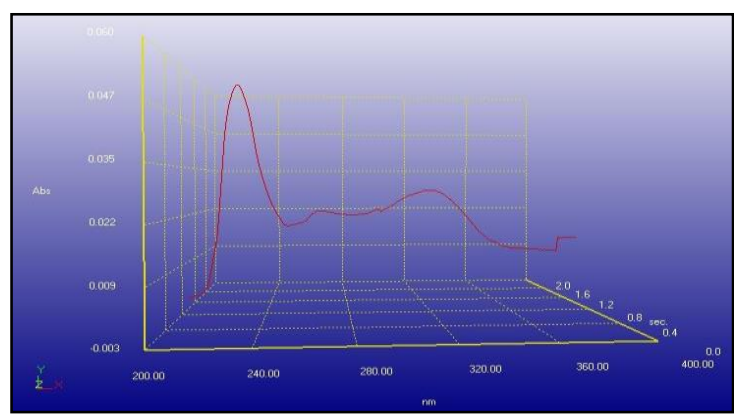

Figure 4: 3 D Spectrum of determination of $\lambda_{\max }$ of Simvastatin
Calibration curve of Simvastatin at $\lambda$ max $225 \mathrm{~nm}$ Observation table:

Table 9: Calibration curve of Simvastatin

\begin{tabular}{|c|c|c|}
\hline S. No. & Conc. $(\boldsymbol{\mu g} / \mathbf{m l})$ & Absorbance \\
\hline 1 & 10 & 0.117 \\
\hline 2 & 20 & 0.213 \\
\hline 3 & 30 & 0.318 \\
\hline 4 & 40 & 0.398 \\
\hline 5 & 50 & 0.497 \\
\hline
\end{tabular}

\section{Preparation and Characterization}

\section{Formulation Development}

Drug encapsulated Liposphere were developed by melt dispersion technique. The formulation of different batches is depicted in Table. Briefly, the lipid core was melted on a water bath maintained at $70-72^{\circ} \mathrm{C}$. Finely powdered drug was dispersed into the molten lipidic phase. The aqueous phase was prepared by heating a blend of water and surfactant to $70-72^{\circ} \mathrm{C}$ with a stabilizer. The molten lipidic phase was slowly transfered to the hot aqueous phase (o/w emulsion) and the emulsification was assisted by stirring the content on a sonicator continuously. The milky dispersion was then rapidly cooled to $20^{\circ} \mathrm{C}$ by immersing the formulation in an ice bath without stopping the agitation to yield a uniform dispersion of lipospheres. The obtained lipospheres were then washed with water and isolated byfiltration.

Table 10: Preparation of Liposphere of Simvastatin

\begin{tabular}{|c|c|c|c|c|c|c|}
\hline \multirow{2}{*}{ F. Code } & \multirow{2}{*}{ Drug (mg) } & Stearic acid & Cetyl alcohol & $\begin{array}{c}\text { Tween 80 as } \\
\text { Surfactant (ml) }\end{array}$ & $\begin{array}{c}\text { Gelatin or pectin } \\
\text { as Stabilizer } \\
\text { (mg) }\end{array}$ & $\begin{array}{c}\text { Water } \\
\text { (ml) }\end{array}$ \\
\cline { 3 - 6 } & & & & $2 \mathrm{ml}$ & 2 & 98 \\
\hline F1 & 20 & 100 & 400 & $2 \mathrm{ml}$ & 2 & 98 \\
\hline F2 & 20 & 150 & 350 & $2 \mathrm{ml}$ & 2 & 98 \\
\hline F3 & 20 & 200 & 300 & $2 \mathrm{ml}$ & 2 & 98 \\
\hline F4 & 20 & 250 & 250 & $2 \mathrm{ml}$ & 2 & 98 \\
\hline F5 & 20 & 300 & 200 & $2 \mathrm{ml}$ & 2 & 98 \\
\hline F6 & 20 & 350 & 150 & $2 \mathrm{ml}$ & & 9 \\
\hline F7 & 20 & 400 & 100 & & & 98 \\
\hline
\end{tabular}




\section{Characterization ofSimvastatin encapsulated lipospheres}

\section{Percentage Yield of Lipospheres}

Yield of Lipospheres percent w/w was calculated according to the formula

$\%$ Yield $=$ Weight of lipospheres $/ \mathrm{Wt}$. of Drug $+\mathrm{Wt}$. of Excipients

\section{Drug loading and Entrapment efficiency}

The amount of Simvastatin present in lipospheres was determined by taking the known amount of lipospheres in which $20 \mathrm{mg}$ of drug should be present theoretically. Then the lipospheres were crushed and the powdered microspheres was taken and dissolved in $10 \mathrm{ml}$ of methanol and stirred for 15 minutes with an interval of 5 minutes and allowed to keep for 24 hours. Then the solution was filtered through whatmann filter paper. Then the absorbance after appropriate dilution was measured spectrophotometrically at $225 \mathrm{~nm}$ by UV-visible spectrophotometer.

Drug entrapment efficiency $(\%)=($ Experimental drug content/Initial drug content in the formulation) $\times 100$

Drug Loading $(\%)=($ Quantity of drug present in the Liposphere/Weight of Lipospheres) $\times 100$

\section{Microscopic Evaluation}

An optical microscope (Olympus-Cover-018) with a camera attachment (Minolta) was used to observe the shape of the prepared microspheres for each drug:lipid ratio.

\section{Measurement of mean particle size}

The mean size of the lipospheres was determined by Photo Correlation Spectroscopy (PCS) on a submicron particle size analyzer (Horiba Instruments) at a scattering angle of $90^{\circ}$. A sample $(0.5 \mathrm{mg})$ of the lipospheres suspended in $5 \mathrm{ml}$ of distilled water was used for the measurement.

\section{Determination of zeta potential}

The zeta potential of the drug- loaded lipospheres was measured on a zeta sizer (Horiba Instruments) by determining the electrophoretic mobility in a micro electrophoresis flow cell. All the samples were measured in water.

\section{Surface morphology Scanning electron microscopy}

Morphology and surface topography of the lipospheres were examined by scanning electron microscopy. The lipospheres from the optimized batch were mounted on the SEM sample stab using a double-sided sticking tape and coated with gold $(\sim 200 \mathrm{~nm})$ under reduced pressure $(0.133 \mathrm{~Pa})$ for $5 \mathrm{~min}$ using an Ion sputtering device. The gold coated lipospheres were observed under the scanning electron microscope and photomicrographs of suitable magnifications were obtained.

\section{Flow property determination of the Lipospheres}

Angle of repose $(\boldsymbol{\theta})$ : The frictional forces in a loose powder or granules or lipospheres can be measured by the angle of repose. This is the maximum angle possible between the surface of a pile of powder or granules and the horizontal plane.

$$
\begin{aligned}
& \tan \theta=h / r \\
& \theta=\tan ^{-1}(\mathrm{~h} / \mathrm{r})
\end{aligned}
$$

Where, $\theta$ is the angle of repose, $\mathrm{h}$ is the height, $\mathrm{r}$ is the radius. The lipospheres were allowed to flow through the funnel fixed to a stand at definite height. The angle of repose was then calculated by measuring the height and radius of the heap of granules formed.

Bulk density Both loose bulk density (LBD) and tapped bulk density (TBD) were determined. Accurately weighed amount of granules taken in a $50 \mathrm{ml}$ capacity measuring cylinder was tapped for 100 times on a plane hard wooden surface and estimated the LBD and TBD, calculated by using following formulas.

$$
\begin{gathered}
\text { LBD (Loose Bulk Density) }=\frac{\text { Mass of Powder }}{\text { Volume of Packing }} \\
\text { TBD (Tapped Bulk Density) }=\quad \begin{array}{l}
\text { Mass of Powder } \\
\text { Tapped Volume of Packing }
\end{array}
\end{gathered}
$$

Compressibility index: Percent compressibility of powder mix was determined by Carr's compressibility index, calculated by using following formula:-

$$
\text { Carr's Index } \%=\frac{\text { TBD }- \text { LBD }}{\text { TBD }} \times 100
$$

Table 11: Grading of flow properties according to Carr's Index

\begin{tabular}{|c|c|c|}
\hline S. No. & $\begin{array}{c}\text { Carr's Compressibility } \\
\text { index }\end{array}$ & Flow \\
\hline 1. & $5-15$ & Excellent \\
\hline 2. & $12-16$ & Good \\
\hline 3. & $* 18-21$ & Fair to passable \\
\hline 4. & $* 23-35$ & Poor \\
\hline 5. & $33-38$ & Very poor \\
\hline 6. & $>40$ & Very very poor \\
\hline
\end{tabular}

*Adding glidant e.g. Talc should improve the flow properties

\section{In-vitro Drug Release Studies}

The dissolution of Simvastatin from the prepared lipospheres was monitored using USP XXV paddle II apparatus. The Amount of the lipospheres equivalent to $20 \mathrm{mg}$ of Simvastatin was dispersed into the dissolution medium. The dissolution media was $900 \mathrm{ml}$ of $\mathrm{pH} 1.2$ buffers maintained at $37 \pm 0.5^{\circ} \mathrm{C}$ and rotating at $50 \pm 1 \mathrm{rpm}$. The $5 \mathrm{ml}$ aliquots were withdrawn at pre-determined time intervals and the withdrawn samples were replaced with fresh dissolution medium. The samples were then analyzed spectrophotometrically at $225.0 \mathrm{~nm}$ for Simvastatin content.

\section{RESULT AND DISCUSSION}

\section{Characterization of Simvastatin encapsulated lipospheres}

\section{Percentage Yield of lipospheres}

Table 12: Percentage yields of lipospheres

\begin{tabular}{|c|c|}
\hline Formulation Code & \% Yield \\
\hline F1 & $68.98 \pm 0.45$ \\
\hline F2 & $65.45 \pm 0.65$ \\
\hline F3 & $60.25 \pm 0.47$ \\
\hline F4 & $73.32 \pm 0.65$ \\
\hline F5 & $69.98 \pm 0.48$ \\
\hline F6 & $68.45 \pm 0.95$ \\
\hline F7 & $65.12 \pm 0.47$ \\
\hline
\end{tabular}


Drug loading and Entrapment efficiency

Table 13: \% Drug entrapment efficiency

\begin{tabular}{|c|c|}
\hline Formulation Code & \% Drug entrapment efficiency \\
\hline F1 & $71.65 \pm 0.45$ \\
\hline F2 & $70.12 \pm 0.25$ \\
\hline F3 & $65.45 \pm 0.32$ \\
\hline F4 & $76.65 \pm 0.14$ \\
\hline F5 & $71.12 \pm 0.56$ \\
\hline F6 & $70.36 \pm 0.65$ \\
\hline F7 & $68.89 \pm 0.74$ \\
\hline
\end{tabular}

Microscopic Evaluation An optical microscope (MSW) with a camera attachment (olympus) was used to observe the shape of the prepared microspheres for each drug: lipid ratio.

\section{Particle size}

The mean size of the lipospheres was determined by photo correlation spectroscopy (PCS) on a submicron particle size analyzer (Horiba Instruments) at a scattering angle of $90^{\circ}$. A sample $(0.5 \mathrm{mg})$ of the lipospheres suspended in $5 \mathrm{ml}$ of distilled water was used for the measurement. The results of measurement of mean particle size of optimized formulation F4 lipospheres were found $250.9 \mathrm{~nm}$.

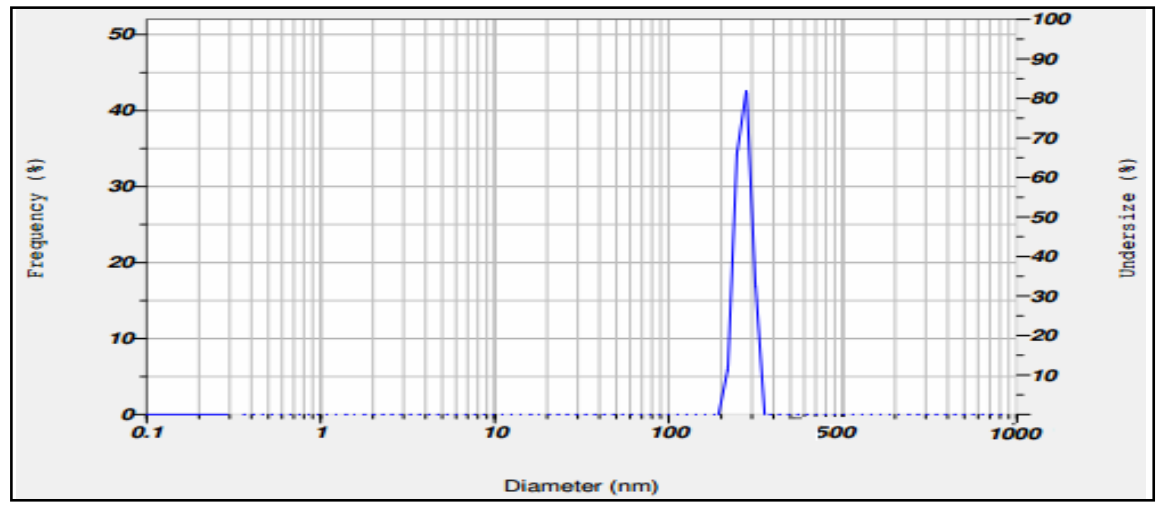

Figure 5: Particle size data of lipospheres

\section{Zeta Potential}

The zeta potential of the drug- loaded lipospheres was measured on a zeta sizer (Malvern Instruments) by determining the electrophoretic mobility in a micro electrophoresis flow cell. All the samples were measured in water Results of zeta potential of optimized formulation F4 lipospheres was found $-10.7 \mathrm{mV}$ respectively.

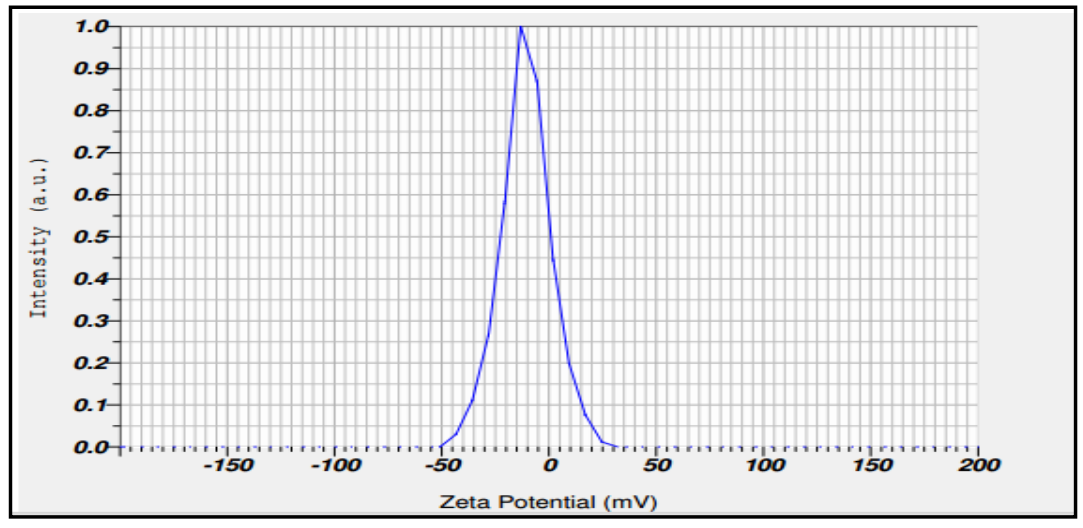

Figure 6: Zeta potential data of lipospheres

\section{Surface morphology Scanning electron microscopy}

Morphology and surface topography of the lipospheres were examined by scanning electron microscopy. The lipospheres from the optimized batch were mounted on the SEM sample stab using a double-sided sticking tape and coated with gold $(\sim 200 \mathrm{~nm})$ under reduced pressure $(0.133$ $\mathrm{Pa}$ ) for 5 min using an Ion sputtering device. The gold coated lipospheres were observed under the scanning electron microscope and photomicrographs of suitable magnifications were obtained.

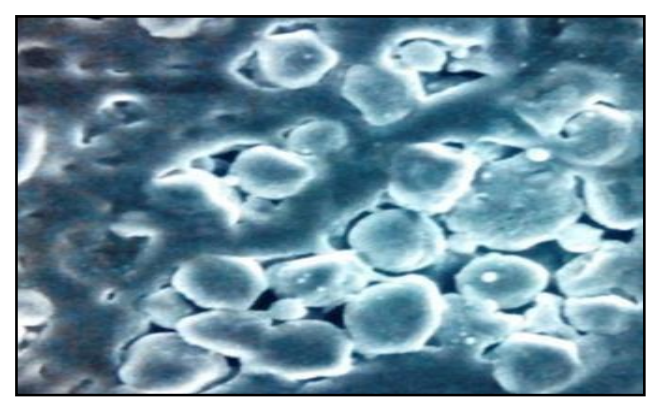

Figure 7: SEM Image of Optimized Formulation

Flow property determination of the Lipospheres 
Angle of repose ( $\boldsymbol{\theta})$ : The frictional forces in a loose powder or granules or lipospheres can be measured by the angle of repose. This is the maximum angle possible between the surface of a pile of powder or granules and the horizontal plane.

Table 14: Relationship between Angle of Repose ( $\theta$ ) and flow properties

\begin{tabular}{|c|c|c|}
\hline S. No. & $\begin{array}{c}\text { Angle of Repose ( } \boldsymbol{\theta} \text { ) } \\
\text { (degrees) }\end{array}$ & Flow \\
\hline 1. & $<25$ & Excellent \\
\hline 2. & $25-30$ & Good \\
\hline 3. & $30-40$ & Passable* \\
\hline 4. & $>40$ & Very poor \\
\hline
\end{tabular}

*Adding glidant E.g. Talc may improve flow properties

Carr's Compressibility index: Percent compressibility of powder mix was determined by Carr's compressibility index, calculated by using following formula:-
Table 15: Grading of the powders flow properties according to Carr's Index

\begin{tabular}{|c|c|c|}
\hline S. No. & $\begin{array}{c}\text { Carr's Compressibility } \\
\text { index }\end{array}$ & Flow \\
\hline 1. & $5-15$ & Excellent \\
\hline 2. & $12-16$ & Good \\
\hline 3. & $* 18-21$ & Fair to passable \\
\hline 4. & $* 23-35$ & Poor \\
\hline 5. & $33-38$ & Very very poor \\
\hline 6. & $>40$ & \\
\hline
\end{tabular}

*Adding glidant E.g. Talc should improve the flow properties

Table 16: Result of Flow Properties Optimized Formulation

\begin{tabular}{|c|c|c|c|c|c|}
\hline \multirow{2}{*}{$\begin{array}{c}\text { Formulation } \\
\text { code }\end{array}$} & \multicolumn{5}{|c|}{ Parameters } \\
\cline { 2 - 6 } & $\begin{array}{c}\text { Loose Bulk } \\
\text { density(gm/ml) }\end{array}$ & $\begin{array}{c}\text { Tapped bulk } \\
\text { density(gm/ml) }\end{array}$ & $\begin{array}{c}\text { Carr's Index } \\
\text { (\%) }\end{array}$ & $\begin{array}{c}\text { Hausner's } \\
\text { Ratio }\end{array}$ & $\begin{array}{c}\text { Angle of } \\
\text { Repose }\end{array}$ \\
\hline F1 & 1.25 & 1.42 & 11.972 & 0.170 & 32.2 \\
\hline F2 & 1.21 & 1.39 & 12.950 & 0.180 & 33.45 \\
\hline F3 & 1.10 & 1.21 & 9.091 & 0.110 & 34.58 \\
\hline F4 & 1.26 & 1.44 & 12.500 & 0.180 & 31.25 \\
\hline F5 & 1.28 & 1.43 & 10.490 & 0.150 & 33.14 \\
\hline F6 & 1.20 & 1.38 & 13.043 & 0.180 & 32.45 \\
\hline F7 & 1.21 & 1.38 & 12.319 & 0.170 & 35.45 \\
\hline
\end{tabular}

\section{Drug Release Studies}

Table 17: Release study of Formulation F-4

\begin{tabular}{|c|c|c|c|c|c|c|}
\hline $\begin{array}{c}\text { Time } \\
\text { (h) }\end{array}$ & $\begin{array}{c}\text { Square Root } \\
\text { of } \\
\text { Time(h) }(\mathbf{h})^{1 / 2}\end{array}$ & Log Time & $\begin{array}{c}\text { Cumulative* }^{*} \\
\text { \% Drug Release }\end{array}$ & $\begin{array}{c}\text { Log } \\
\text { Cumulative } \\
\text { \% Drug Release }\end{array}$ & $\begin{array}{c}\text { Cumulative } \\
\text { \% Drug } \\
\text { Remaining }\end{array}$ & $\begin{array}{c}\text { Log } \\
\text { Cumulative } \\
\text { \% Drug Remaining }\end{array}$ \\
\hline 0.5 & 0.707 & -0.301 & 19.65 & 1.293 & 80.35 & 1.905 \\
\hline 1 & 1 & 0 & 32.15 & 1.507 & 67.85 & 1.832 \\
\hline 1.5 & 1.225 & 0.176 & 40.25 & 1.605 & 59.75 & 1.776 \\
\hline 2 & 1.414 & 0.301 & 48.78 & 1.688 & 51.22 & 1.709 \\
\hline 3 & 1.732 & 0.477 & 59.98 & 1.778 & 40.02 & 1.602 \\
\hline 4 & 2 & 0.602 & 65.45 & 1.816 & 34.55 & 1.538 \\
\hline 6 & 2.449 & 0.778 & 75.65 & 1.879 & 24.35 & 1.386 \\
\hline 8 & 2.828 & 0.903 & 82.23 & 1.915 & 17.77 & 1.250 \\
\hline 12 & 3.464 & 1.079 & 95.45 & 1.980 & 4.55 & 0.658 \\
\hline
\end{tabular}


Table 18: Comparative study of regression coefficient for selection of optimize batch

\begin{tabular}{|c|c|c|c|}
\hline Zero order & First order & Higuchi & Korsmayer \\
\hline $\mathrm{R}^{2}=0.874$ & $\mathrm{R}^{2}=0.980$ & $\mathrm{R}^{2}=0.969$ & $\mathrm{R}^{2}=0.971$ \\
\hline
\end{tabular}

The In vitro drug release data of the optimized formulation was subjected to goodness of fit test by linear regression analysis according to zero order, first order kinetic equsation, Higuchi's and Korsmeyer's models in order to determine the mechanism of drug release. When the regression coefficient values of were compared, it was observed that ' $r$ ' values of First order was maximum i.e 0.980 hence indicating drug release from formulations was found to follow First order release kinetics.

Simvastatin is a lipid- lowering agent that is derived synthetically from the fermentation of Aspergillus terreus. Color of Simvastatin was found white crystalline powder and Odorless. Solubility study of Simvastatin has been done in various solvent such as water, ethanol, methanol, acetone 0.1 $\mathrm{N} \mathrm{NaOH}$ and $0.1 \mathrm{~N} \mathrm{HCl}$ solution. We were found that a solubility of Simvastatin was sparingly soluble in water, soluble in $0.1 \mathrm{~N} \mathrm{HCl}$, methanol and ethanol solution, Sparingly Soluble in $0.1 \mathrm{~N} \mathrm{NaOH}$. The $\mathrm{pH}$ of Simvastatin was found 7.61. The percentage of loss on drying was found $1.1 \%$ $\mathrm{w} / \mathrm{w}$. It means drug was free flowing in nature. The $\lambda$ max of Simvastatin was determined by running the spectrum of drug solution in double beam ultraviolet spectrophotometer. The spectrum of this solution was run $200-400 \mathrm{~nm}$ range in U.V. spectrophotometer. The $\lambda$ max of Simvastatin was found $225.0 \mathrm{~nm}$. The standard solution of drug was prepared in different conc. in $0.1 \mathrm{~N} \mathrm{HCl}$ and plotted the graph between conc. and absorbance. The plot of absorbance vs. concentration was plotted and on the absorption point the linear line was determined which follows Beer's Lambert law. The linear regression analysis was done on Absorbance data points. The value of Slope, Intercept and Correlation coefficient were found $0.009,0.012$ and 0.997 respectively.

\section{CONCLUSION}

Lipospheres well comply with the needs of the drug development process, as for instance safety, stability, different application's fields (pharmaceutical, veterinary, cosmetic as well as food additives) and administration pathways (oral, mucosal and topical delivery), ease of modifying the release of APIs, taste masking ability, rapidity and availability of several processing techniques. Moreover, advances in solvent free process technologies have greatly improved the potential for successful lipid based formulations without surfactants included. Simvastatin loaded lipospheres were prepared successfully by melt dispersion technique and evaluated for percentage yield of lipospheres, drug loading and entrapment efficiency, microscopic evaluation, scanning electron microscopy, Flow property determination and In vitro drug release study.
Formulation F-4 the optimized batch was the best among all batches and found potential for further development.

\section{ACKNOWLEDGMENTS}

We are thankful to Dr. Mohd. Azaz Khan, Director and Dr. Megha Jha, Manager (Research and Development), Pinnacle Biomedical Research Institute (PBRI) Bhopal, India to provide us all lab facilities.

\section{REFERENCES}

1. Galgatte UC, Bhosale UM, Chaudhari PD, Formulation Development, Optimization and In-vitro Evaluation of Glimepiride Lipospheres, Int. J. Pharm. Sci. Rev. Res., 2015; 34:157-162.

2. Osama AA Ahmed, Khaled M Hosny, Majid M Al-Sawahli, Usama AFahmy, Optimization of caseinate-coated simvastatin- zein nanoparticles: improved bioavailability and modified release characteristics Drug Design, Development and Therapy 2015; 9:655-662.

3. Vijaya Bhaskar N., Ravi Prakash P. and Devanna N., Formulation and characterisation of Simvastatin nanoparticles loaded transdermal patch, Journal of Chemical and Pharmaceutical Research, 2015; 7:1084-1093.

4. Bakliwal AA, Bedse S, Talele SG, Chaudhari GN, Lipospheres: A Novel Approach for Drug Delivery, International Journal of Research in Pharmaceutical and Nano Sciences. 2015; 4:298 306.

5. Kumara JBV, Madhusudhan B, Formulation and Evaluation of Atorvastatin Calcium Loaded Chitosan Nanoparticles, Int J Pharm Bio Sci 2015; 6:50 -58.

6. Momoh MA, Kenechukwu FC, Gwarzo MS, Builders PF, Formulation and Evaluation of Ibuprofen Loaded Lipospheres for Effective Oral Drug Delivery, Dhaka Univ. J. Pharm. Sci., 2015; 14:17-27.

7. Faruksha U, Vetrichelvan T, Formulation, Characterization And Optimization of Pioglitazone Hydrochloride Nanoparticles By Solvent Displacement Method Using $3^{2}$ Factorial Design, International Journal of PharmTech Research, 2013; 5(2):754766.

8. Amsa P, Tamizharasi S, Mohanraj KP, Jagadeeswaran M, Sivakumar T, Formulation Development and In-Vitro Evaluation of Nanosuspension Loaded with Simvastatin, Indo American Journal of Pharmaceutical Research, 2013; 3(12):1531-1539.

9. Mantry S, Reddy KVN, Sahoo CK, Sriram N, Formulation Development and Characterization of Sustained Release Matrix Tablet of Simvastatin Using Natural Polymers, Indo American Journal of Pharmaceutical Research, 2013; 3(5):4031-4041.

10. Khulbe P, Munjal P, Formulation and Evaluation of Vinpocetine Loaded Lipospheres, Int J Pharm Pharm Sci, 2012; 4(3):470-473.

11. Bathool A, Vishakante GD, Khan MS, Shivakumar HG, Development and characterization of atorvastatin calcium loaded chitosan nanoparticles for sustain drug delivery, Adv. Mat. Lett. 2012; 3(6):466-470. 